\title{
Analysis of selected physical fitness variable speed on BMI classification of women students
}

- SUBITHA MATHEW AND V. MAHADEVAN ${ }^{1}$

Received : 02.12.2014; Accepted : 28.03.2015

Members of the Research Forum Associated Authors: ${ }^{1}$ Department of Physical Education and Yoga, University of Madras, Chetpet, CHENNAI (T.N.) INDIA

Author for correspondence : SUBITHA MATHEW Department of Physical Education and Yoga, University of Madras, Chetpet, CHENNAI (T.N.) INDIA Email: subithamathew@gmail.com

\section{-ABSTRACT}

The purpose of the study was to critically analysis the selected physical fitness variable speed on BMI classification of women students. To achieve the purpose sixty women students were selected as subjects on the basis of body mass index from Pondicherry University. The subjects were divided into four groups namely underweight, normal weight, over weight and obesity consisting of fifteen students in each group. The subject's age ranged between 18 to 25 years. Data were collected on the selected variable namely Speed. One way analysis of variance (ANOVA) was used for statistical analysis. The result of the study showed that there was significant difference on speed among BMI classification of women students.

- KEY WORDS : BMI, Speed, Women students, Physical fitness

- HOW TO CITE THIS PAPER : Mathew, Subitha and Mahadevan, V. (2015). Analysis of selected physical fitness variable speed on BMI classification of women students. Internat. J. Phy. Edu., 8 (1) : 6971. 